\title{
Replacement of grains with soybean hulls ameliorates SARA-induced impairment of the colonic epithelium barrier function of goats
}

Kai Zhang ${ }^{1,2}$, Yuanlu Tu ${ }^{1,2}$, Lipeng Gao ${ }^{1,2}$, Meijuan Meng ${ }^{1,2}$ and Yunfeng Bai ${ }^{1,2^{*}}$ (D)

\begin{abstract}
Background: The effect of soybean hull feeding on the disruption of colonic epithelium barrier function was investigated in goats fed a high-concentrate diet. Twenty-one Boer goats (live weight, $32.57 \pm 2.26 \mathrm{~kg}$; age, 1 year) were randomly divided into three groups: low-concentrate diet (LC), high-concentrate diet (HC), and high-concentrate diet with soybean hulls (SH).

Results: We found that the rumen fluid in the LC and SH group shown a higher pH value compared with the HC group. The mRNA and protein expression levels of extracellular regulated protein kinase (ERK), c-Jun $\mathrm{N}$-terminal kinase (JNK), and p38 mitogen-activated protein kinase (MAPK) in the colonic epithelium were significantly decreased in the SH group than in the HC group. Moreover, in goats fed the HC diet, SH treatment promoted gene expression and protein abundance of claudin-1, claudin-4, occludin, and ZO-1 in the colonic epithelium. Additionally, the injury to the colonic epithelium barrier caused by the HC diet was reversed by SH treatment.

Conclusions: Our results indicated that supplemental SH feeding reverses the damage to colonic epithelium tight junctions by inhibiting the MAPK signalling pathway and has a protective effect on the colonic epithelium during SARA.
\end{abstract}

Keywords: Goat, SARA, Colonic epithelium, Soybean hulls, Tight junction proteins

\section{Background}

Ruminants are always fed a large amount of cereals in their diet to meet the nutritional requirements for energy for rapid weight gain or high milk yields. Although grains are beneficial in the short term, the risk of a metabolic disorder and systemic disease termed subacute rumen acidosis (SARA) increases after long-term feeding [1]. A ruminal $\mathrm{pH}$ between 5.6 and 5.8 not less than $3 \mathrm{~h}$ per day is the most widely accepted parameter in the diagnosis of SARA $[2,3]$. This low ruminal $\mathrm{pH}$ perturbs the balance of rumen microbial populations, which is directly related

\footnotetext{
* Correspondence: blinkeye@126.com

${ }^{1}$ Circular Agriculture Research Center, Jiangsu Academy of Agricultural Sciences, Nanjing, China

${ }^{2}$ Key Laboratory of Crop and Livestock Integrated Farming, Ministry of Agriculture, Nanjing, China
}

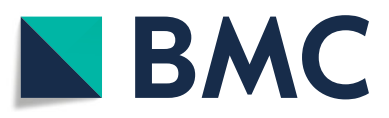

(c) The Author(s). 2018 Open Access This article is distributed under the terms of the Creative Commons Attribution 4.0 International License (http://creativecommons.org/licenses/by/4.0/), which permits unrestricted use, distribution, and reproduction in any medium, provided you give appropriate credit to the original author(s) and the source, provide a link to the Creative Commons license, and indicate if changes were made. The Creative Commons Public Domain Dedication waiver (http://creativecommons.org/publicdomain/zero/1.0/) applies to the data made available in this article, unless otherwise stated. to the release of lipopolysaccharide (LPS) endotoxin from lysed bacteria in the gastrointestinal tract and to damage to the gastrointestinal epithelium $[4,5]$. Free LPS can be translocated from this dietary-induced damage to the gut mucosa, causing a systemic inflammatory response [6-8].

The colonic epithelium is a polarized monolayer of columnar epithelial cells that form a semipermeable paracellular diffusion barrier for nutrient absorption and metabolism, prohibiting the transportation of microbes and toxins under the normal physiological state [9]. However, the barrier properties of the gastrointestinal epithelium can be damaged by low $\mathrm{pH}$ and hyperosmolarity when SARA occurs, resulting in increased translocation of LPS into circulation [10, 11]. Epithelial cells form selective barriers with an elaborate network of 
intercellular protein complexes tight junctions (TJs). TJs regulate integral mechanisms of epithelial morphogenesis, which are crucial for proper function and formation of epithelial barriers. The transmembrane proteins claudins and occludin and cytoplasmic plaque composed of the proteins zonula occludins (ZO)-1, -2 , and -3 are by far the most important for TJs [12-14].

The abnormal expression of $\mathrm{TJ}$ protein can lead to the impairment of the colon barrier [15]. The expression of occludin is correlated with various barrier properties $[16,17]$, and overexpression of occludin leads to changes in the gate and fence function of TJs in mammalian epithelial cells $[18,19]$. Additionally, the occludin loop peptides can lead to the disappearance of TJs [20]. Although tight junctions exhibit normal barrier properties in occludin-knockout mice, complex abnormalities are observed, with postnatal growth retardation, the absence of fertility, the thinning of compact bone, chronic inflammation and hyperplasia [21, 22]. Claudins are identified as key molecules in the barrier function of TJs [23]. Overexpression of claudin-1 and -2 in fibroblasts can reconstitute tight junction strands [24], and multiple lines of evidence suggest that overexpression or knockout of claudins can ameliorate junctional ion permeability and barrier function $[25,26]$. $\mathrm{ZO}-1$, the first tight junction protein identified, interacts with multiple other junctional components, including claudins and occludin [27]. A previous study demonstrated that TJ barrier formation disintegrated because of the depletion of $\mathrm{ZO}-1$ in cultured epithelial cells [28]. Moreover, claudin and occludin cannot constitute a normal $\mathrm{TJ}$ structure in ZO-depleted cells. MAPK signalling pathways regulate the expression of $\mathrm{TJ}$ proteins. We found that the activity of the MAPK signalling pathway can disrupt epithelial barrier function together with a decrease transcriptional level in claudin-1, occludin, and ZO-1 [29, 30].

Recently, replacing grain with low-starch, nonforage fibre has become a potential alternative to prevent SARA occurrence. A previous study demonstrated that partial substitution of starch with nonforage fibre sources, such as soybean hulls, positively affected milk production and composition in lactating dairy cows. Moreover, this substitution can increase feed efficiency and decrease diet feed costs [31]. Our previous studies have indicated that soybean hulls are traditionally fed as a protein supplement to improve the low rumen $\mathrm{pH}$ induced by SARA and do not affect the performance of goats. However, little is known about whether soybean hulls can prevent colonic epithelial barrier dysfunction when grain-induced SARA occurs. Therefore, the present study was conducted to confirm that soybean hulls increase the expression of TJs through modification and signalling pathway regulation, to provide a new treatment option for impaired barrier function.

\section{Results}

\section{Rumen $\mathrm{pH}$ value analysis}

The average rumen $\mathrm{pH}$ value in the $\mathrm{LC}$ and $\mathrm{SH}$ group was markedly higher than that in the HC group (Fig. 1, $P<0.05)$. A reduced $\mathrm{pH}$ value between 5.6 and 5.8 was approximately $4 \mathrm{~h} /$ day in the $\mathrm{HC}$ group of animals. The rumen $\mathrm{pH}$ value in the $\mathrm{LC}$ and $\mathrm{SH}$ groups was similar.

\section{$\mathrm{pH}$ and LPS content in the colon and LPS and cytokines in plasma}

Colonic $\mathrm{pH}$ value decreased from 6.90 for the LC group to 5.98 for the $\mathrm{HC}$ group (Table $1, P<0.05$ ). There was no significant difference in the colonic $\mathrm{pH}$ between the LC and SH groups.

Colonic content and plasma LPS concentration in the LC and SH group was significantly lower than that in the HC group $(P<0.01)$, while the concentration of LPS in the $\mathrm{LC}$ and $\mathrm{SH}$ groups was similar, as shown in Table 1 .

IL-1 $\beta$, IL-6, and TNF- $\alpha$ concentrations in the HC group were significantly increased $(P<0.01$, Table 1$)$ compared with those in the LC group, while the concentrations of IL- $1 \beta$ and IL- 6 had no significant difference between the $\mathrm{SH}$ group and LC group. The level of TNF- $\alpha$ was significantly higher in the SH group than in the LC group $(P<0.05$, Table 1$)$.

\section{Morphological analysis of the colonic epithelium}

The epithelial injury scores confirmed the results of the colonic epithelium histological analysis, as shown in Fig. 2. The epithelial surface of colonic epithelium was sloughed in the $\mathrm{HC}$ group, while it in the LC and $\mathrm{SH}$ group covered by mucus and remained intact. Although the inflammatory cells in the colom serosal muscle layer of the $\mathrm{SH}$ group were more than the LC group, it was much less than the $\mathrm{HC}$ group. A

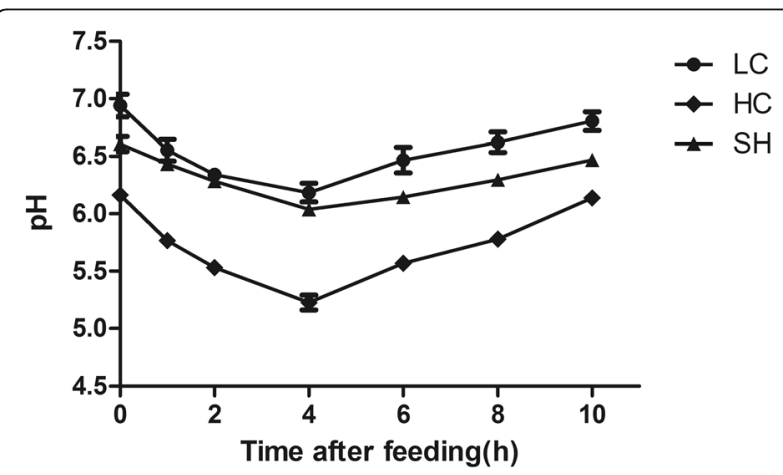

Fig. 1 Rumen $\mathrm{pH}$ value of different groups at different time points after feeding. The $\mathrm{pH}$ was markedly decreased in the $\mathrm{HC}$ group. With supplemental feeding with soybean hulls $(\mathrm{SH})$, the $\mathrm{pH}$ changed significantly compared with that in the HC group. The error bars indicate the standard error of the mean. All of the data are shown as the mean \pm SD. Differences between two groups were considered significant when $P<0.05$ 
Table 1 LPS and primary pro-inflammatory cytokines content of different groups

\begin{tabular}{llll}
\hline Item & LC & $H C$ & SH \\
\hline pH in colon & $6.90^{\mathrm{a}} \pm 0.34$ & $5.98^{\mathrm{b}} \pm 0.42$ & $6.73^{\mathrm{a}} \pm 0.28$ \\
LPS in colon, $\mathrm{kEU} / \mathrm{mL}$ & $27.64^{\mathrm{b}} \pm 2.96$ & $56.3^{\mathrm{a}} \pm 3.26$ & $28.3^{\mathrm{b}} \pm 3.83$ \\
LPS in plasma, EU/mL & $0.16^{\mathrm{b}} \pm 0.02$ & $0.96^{\mathrm{a}} \pm 0.35$ & $0.23^{\mathrm{b}} \pm 0.06$ \\
IL-1 $\beta$ in plasma, $\mathrm{ng} / \mathrm{mL}$ & $0.162^{\mathrm{b}} \pm 0.013$ & $0.23^{\mathrm{a}} \pm 0.018$ & $0.155^{\mathrm{b}} \pm 0.016$ \\
IL-6 in plasma, $\mathrm{pg} / \mathrm{mL}$ & $15.67^{\mathrm{b}} \pm 1.17$ & $72.2^{\mathrm{a}} \pm 0.68$ & $12.2^{\mathrm{b}} \pm 0.41$ \\
TNF- $a$ in plasma, fmol/mL & $76.73^{\mathrm{c}} \pm 5.32$ & $570.36^{\mathrm{a}} \pm 24.29$ & $354.15^{\mathrm{b}} \pm 51.42$
\end{tabular}

Different characters $(a, b$ and $c)$ show significant difference among diets $(p<0.05)$

high-concentrate diet with soybean hulls feeding had a marked decrease macroscopic damage score compared with the HC group $(P<0.05)$.

\section{Relative expression of genes related to barrier function in} the colonic epithelium

Several pivotal genes were chosen to determine the colonic epithelium barrier function of the goats fed different diets, and the results are shown in Figs. 3 and 4. The mRNA relative expression of ERK1, p38 and JNK, increased in the $\mathrm{HC}$ group compared with that in the LC group $(P<0.01)$, while these in the LC and $\mathrm{SH}$ groups was similar. The expression of ERK2 was also increased markedly in the HC group $(P<0.05)$.

The mRNA expression of claudin-1, claudin-4, occludin, and ZO-1 was also detected by RT-qPCR. The

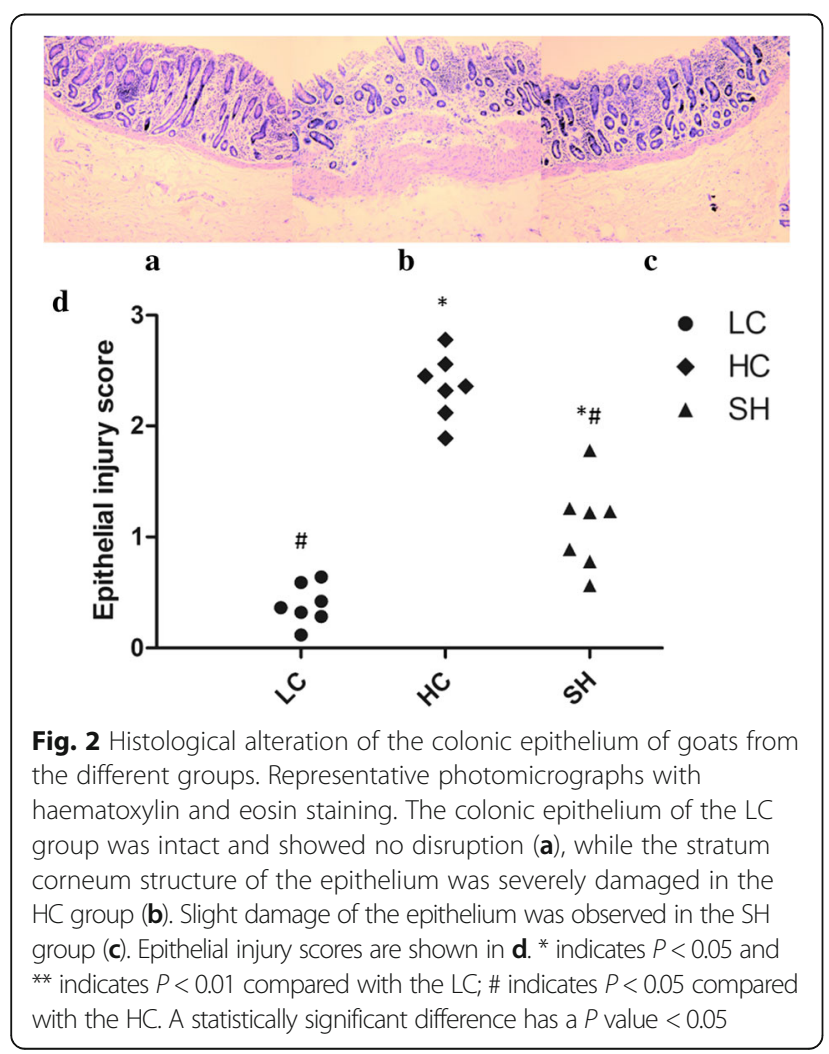

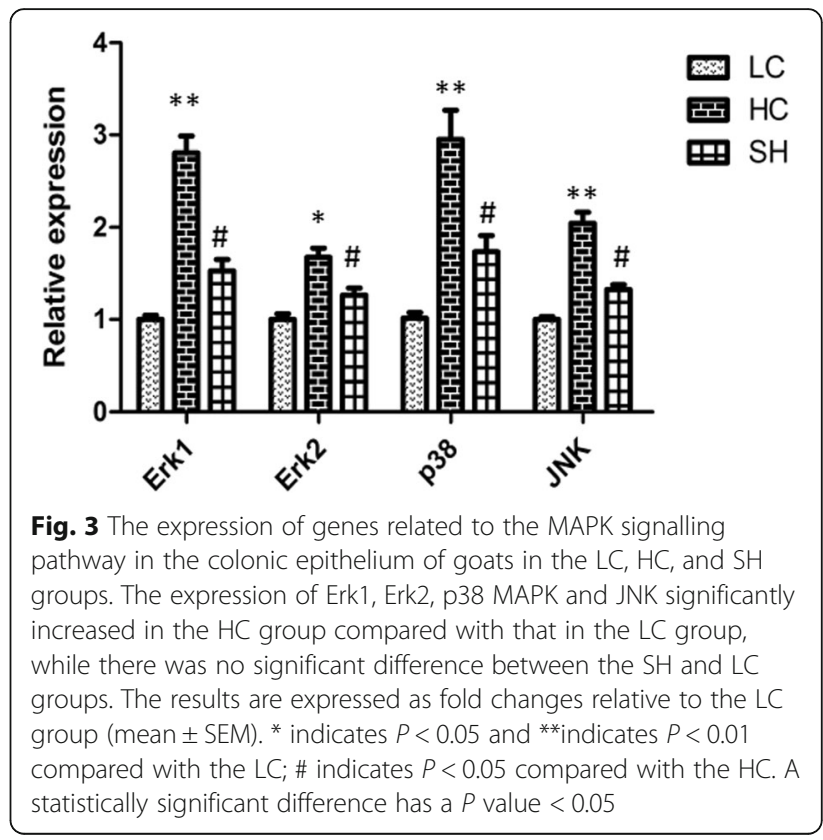

mRNA expression of these genes in the colonic epithelium of goats fed the $\mathrm{HC}$ diet declined significantly compared with the LC group, while the expression in the LC and $\mathrm{SH}$ groups was similar.

\section{Phosphorylation levels of ERK, pERK, JNK, pJNK, p38, and} pp38 in the colonic epithelium

The phosphorylation levels of ERK, p38 and JNK were determined by Western blot analysis (Fig. 5). ERK and JNK phosphorylation levels in the HC group were significantly elevated compared with those in the LC group,

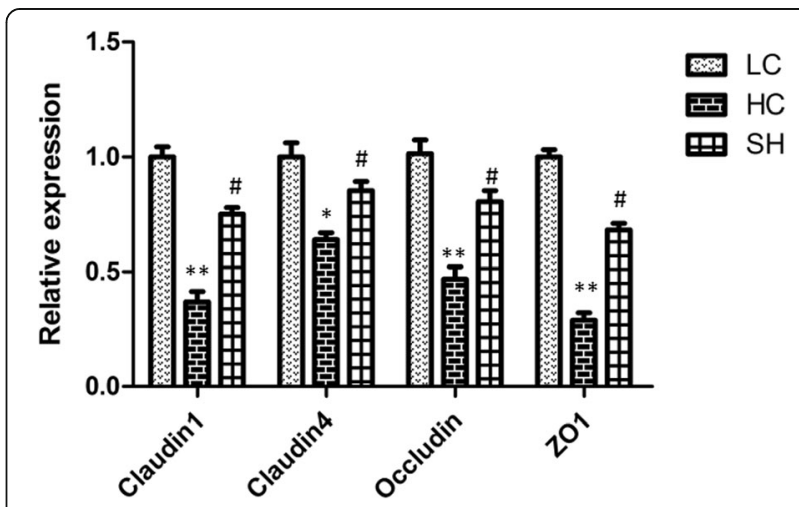

Fig. 4 The expression of genes related to tight junction proteins in the colonic epithelium of goats in the LC, HC, and SH groups. The colonic epithelium of the goat fed the $\mathrm{HC}$ diet had a significant decline in the mRNA expression of claudin-1, claudin-4, occludin, and ZO-1 compared with that in the LC group, while no significant change between the SH and LC groups was observed. The results are expressed as fold changes relative to those in the LC group (mean \pm SEM). ${ }^{*}$ indicates $P<0.05$ and **indicates $P<0.01$ compared with the LC; \# indicates $P<0.05$ compared with the HC. A statistically significant difference has a $P$ value $<0.05$ 


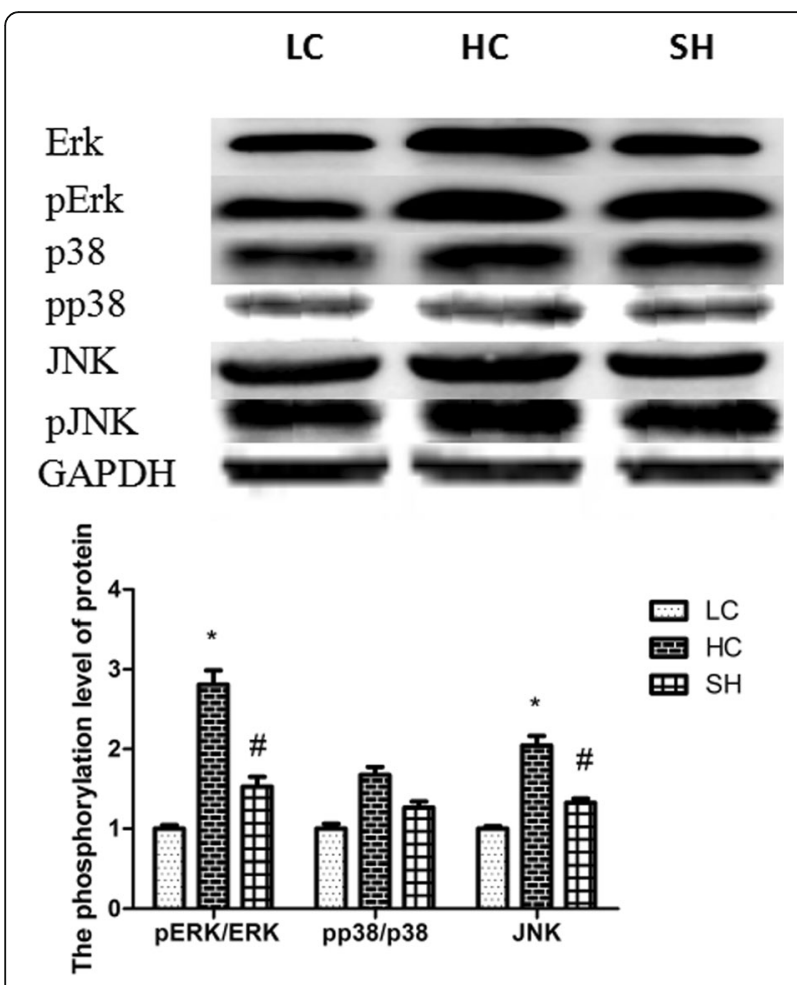

Fig. 5 The phosphorylation levels of Erk, JNK and p38 MAPK in the colonic epithelium of goats in the LC, HC, and SH groups. Erk, JNK and p38 MAPK phosphorylation levels in the HC group were significantly elevated compared with those in the LC group, while the levels in the SH group were not elevated. The results are expressed as fold changes relative to those in the LC group (mean \pm SEM). ${ }^{*}$ indicates $P<0.05$ and ${ }^{* *}$ indicates $P<0.01$ vs the $L C$; \# indicates $P<0.05$ compared with the HC. A statistically significant difference has a $P$ value $<0.05$

while the levels in the $\mathrm{SH}$ group were not elevated. There was no significant difference in the phosphorylation levels of p38 among the treatments.

\section{Protein levels of claudin-1, occludin, and ZO-1 in the colonic epithelium}

Western blotting of claudin-1 and ZO-1 showed significantly lower protein levels in the $\mathrm{HC}$ group than in the LC group, whereas the levels in the $\mathrm{SH}$ and LC groups were similar (Fig. 6). The protein expression of occludin was not significantly different among the three groups.

\section{Discussion}

Feeding an $\mathrm{HC}$ diet to ruminants can not only promote microbial protein synthesis in the rumen and increase growth and milk production but also negatively affect rumen function because of the rapid accumulation of volatile fatty acids (VFA), which leads to decreased ruminal $\mathrm{pH}[32,33]$. Goats fed the $\mathrm{HC}$ diet for 12 weeks exhibited a low rumen $\mathrm{pH}$ between 5.6 and 5.8 for more than $3 \mathrm{~h}$, which met

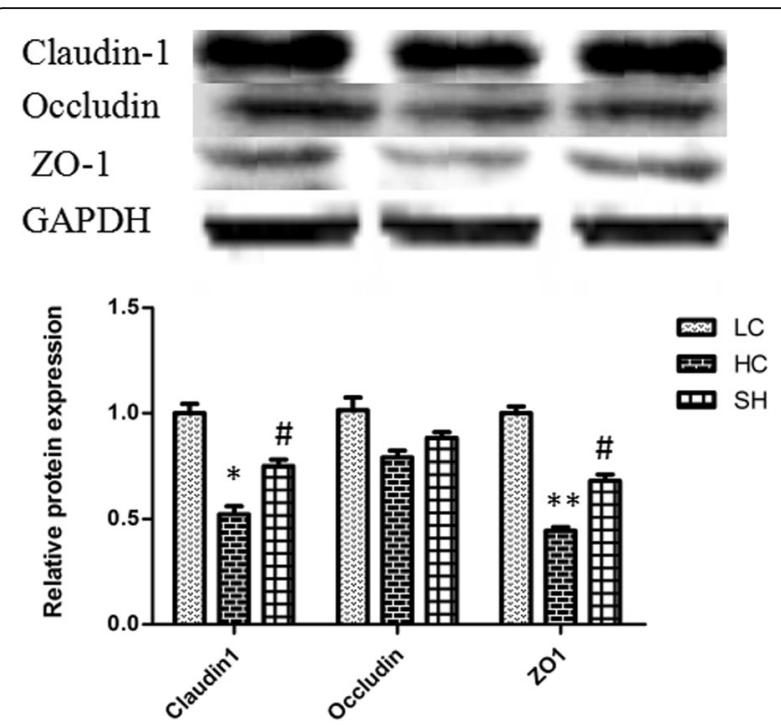

Fig. 6 Protein abundance of claudin-1, occludin, and ZO-1 in the colonic epithelium of goats in the LC, HC, and SH groups. The abundance of claudin-1 and ZO-1 proteins in the HC group significantly decreased compared with that in the LC group, while the levels in the SH group were not significantly altered. The results are expressed as fold changes relative to those in the LC group (mean \pm SEM). ${ }^{*}$ indicates $P<0.05$ and ${ }^{*}{ }^{*}$ indicates $P<0.01$ vs the $L C_{i}$ \# indicates $P<0.05$ compared with the HC. A statistically significant difference has a $P$ value $<0.05$

the current definition of SARA, indicating that SARA was successfully induced by the $\mathrm{HC}$ diet in the present study. We found that supplementing the $\mathrm{HC}$ diet with soybean hulls in the $\mathrm{SH}$ group led to a higher rumen $\mathrm{pH}$ than that in the $\mathrm{HC}$ group. Soybean hulls contain a high concentration of digestible neutral detergent fibre, which can increase chewing time and saliva secretion [31], possibly explaining how the $\mathrm{SH}$ diet increased the rumen $\mathrm{pH}$. A low ruminal $\mathrm{pH}$ leads to gastrointestinal epithelial barrier dysfunction and translocation of LPS, increasing the risk of system inflammatory response [34, 35]. Based on our results, concentrations of LPS in the colon content and plasma of goats in the $\mathrm{HC}$ group were higher than those in the $\mathrm{LC}$ and $\mathrm{SH}$ groups.

Feeding the animals the $\mathrm{HC}$ diet could interrupt the barrier function of the colonic epithelium in our study. The expression of claudin-1, claudin-4, occludin, and ZO-1 declined significantly in the HC group, providing evidence that $\mathrm{HC}$ feeding can modulate the expression of $\mathrm{TJ}$ proteins and disrupt the barrier function. With the addition of $\mathrm{SH}$, the expression of TJs was upregulated to a similar level to the LC group. Claudin-1, claudin-4, and ZO-1 protein abundance in the colonic epithelium of goats in the $\mathrm{HC}$ group was downregulated compared with that in goats treated with $\mathrm{LC}$ and $\mathrm{SH}$. We also found that 
SH diet feeding ameliorated the damage to the colonic epithelial barrier induced by $\mathrm{HC}$ diet feeding through histological alterations.

The MAPK signalling pathway is widely accepted to play a key role in regulating TJ protein formation [36]. JNK is essential in regulating TJ expression and epithelial barrier function. Inhibition of JNK activity in murine mammary epithelial cells can modulate of claudins expression and increase epithelial barrier function [37]. The expression of TJs can be depleted by various stimuli, such as the JNK activator anisomycin and the pro-inflammatory cytokines in human pancreatic cancer cells [38]. Proinflammatory cytokine treatment can induce the expression of $\mathrm{TJ}$ proteins, whereas the change was reversible by a JNK inhibitor. Some studies have indicated that $\mathrm{HC}$ diet feeding could enhance immune gene expression and activate the JNK signalling pathway in the liver of dairy cow [39]. These findings suggest that the concentration of pro-inflammatory cytokines and the phosphorylation level of the JNK pathway could induce disruption of the epithelial barrier. In the current study, the production of IL- $1 \beta$, TNF, and IL- 6 in the $\mathrm{HC}$ group was significantly higher than that in the LC group. The protein expression of JNK and pJNK increased, consistent with the mRNA expression of the corresponding gene by $\mathrm{HC}$ feeding. With $\mathrm{SH}$ administration, the indicators remained at levels similar to those observed in the LC group. The overexpression of the junctional membrane protein occludin can suppress ERK/MAP kinase activation [40]. In our study, the mRNA expression of ERK1 and ERK2 in goats induced by $\mathrm{HC}$ diet feeding declined after $\mathrm{SH}$ treatment, and $\mathrm{SH}$ treatment also decreased the phosphorylation levels of ERK. The expression of claudin- 1 and -2 can be regulated by the p38 activator in vitro [41]. Decreasing expression of claudin-1 in regenerating rat liver has been reported by the p38 MAP kinase inhibitor [42], and p38 MAP kinase and Akt can inhibit the expression of claudin-4 in hepatic cell lines $[43,44]$. Thus, the p38 MAP kinase pathway plays an important role in TJ formation in vivo and in vitro. SH treatment improved the downregulated expression of $\mathrm{p} 38$ induced by the $\mathrm{HC}$ diet in our study, which is consistent with the increased expression of claudin-1 and claudin- 4 in our study. Hence, these lines of evidence collectively prove that the expression of TJs can be regulated by the MAPK signalling pathway in the colonic epithelium of goats.

\section{Conclusions}

According to our results, HC diet feeding for 12 weeks severely compromised the colonic epithelium and impaired epithelial barrier function. These adverse effects were attenuated after SH treatment through the phosphorylation of the MAPK signalling pathway. Thus, a new option can be applied to remedy a series of systemic inflammatory responses induced by $\mathrm{HC}$ diet feeding.

\section{Methods}

Animals, diet, and experimental design

Twenty-one healthy, 1-year-old male Boer goats with an average body weight of $32.57 \pm 2.26 \mathrm{~kg}$, which were purchased from the Luhe Experimental Farm of Jiangsu Academy of Agricultural Sciences, were randomly divided into three groups $(n=7)$ : low-concentrate diet (LC; $70 \%$ forage and 30\% concentrate), high-concentrate diet ( $\mathrm{HC} ; 30 \%$ forage and $70 \%$ concentrate), and high-concentrate diet with soybean hulls (SH; $20 \%$ soybean hulls instead of grain). The diet nutritional composition are shown in Table 2. The goats were fed these diets at 8:00 a.m. and 6:00 p.m. and provided fresh water for 12 weeks.

\section{Sample collection and analysis}

The rumen $\mathrm{pH}$ values were measured on the last day of weeks 10,11 , and 12 through a cannula at $0,1,2,4,6,8$, and $10 \mathrm{~h}$ after feeding by a basic $\mathrm{pH}$ meter.

Blood samples were collected via the lacteal vein into 5 -mL vacuum blood collection tubes. The blood samples were centrifuged at $1500 \times \mathrm{g}$ for $15 \mathrm{~min}$, and the plasma was collected and stored at $-20^{\circ} \mathrm{C}$ for the determination of LPS, IL-1 $\beta$, IL- 6 , and TNF- $\alpha$.

The goats were slaughtered according to the law of Jiangsu Provincial People's Government, China, and the study was approved by the guidelines of Jiangsu Province Animal Regulations (Government Decree No. 45) and the Committee on the Ethics of Animal Experiments of Jiangsu Academy of Agricultural Sciences. The $\mathrm{pH}$ values of colonic digesta samples were immediately measured. Colons were removed and washed with PBS. Colonic tissue sample was selected from the same part of the colon aseptically and divided into two parts. One part was cut into $1 \mathrm{~cm} \times 1 \mathrm{~cm}$ small pieces and infiltrated in $4 \%$ paraformaldehyde solution, and the other part was transferred into liquid nitrogen and then kept at $-80^{\circ} \mathrm{C}$ for later detection.

\section{Determination of LPS content in colon and plasma primary pro-inflammatory cytokines}

LPS concentration in the colon content and plasma was determined with Chromogenic Endpoint Limulus Amebocyte Lysate Assay Kits (Chinese Horseshoe Crab Reagent Manufactory Co., Ltd., Xiamen, China). The detection range of LPS concentrations in colon and plasma were $0.1-1$ endotoxin units $(\mathrm{EU}) / \mathrm{mL}$ and $0.01-$ $0.1 \mathrm{EU} / \mathrm{mL}$, respectively. IL- $1 \beta$, IL- 6 and TNF- $\alpha$ concentrations in the plasma were determined by radioimmunoassay radioimmunoassay kits C09DJB, C12DJB 
Table 2 Ingredients and nutrient composition of experimental diets

\begin{tabular}{llll}
\hline Ingredient,\% DM & \multicolumn{3}{l}{$\begin{array}{l}\text { Percentage (\%)of ingredients in different diets } \\
\text { (air dry matter) }\end{array}$} \\
\cline { 2 - 4 } & LC & HC & SH \\
\hline Maize & 12 & 40 & 21.78 \\
Soybean meal & 11.92 & 6.36 & 5.30 \\
Wheat bran & 1.00 & 8.98 & 8.57 \\
Wheat & 2.09 & 12.00 & 11.83 \\
Soybean hull & 0.00 & 0.00 & 20.00 \\
Straw & 70 & 30 & 30 \\
Calcium hydphosphate & 1.40 & 0.55 & 0.80 \\
Limestone & 0.59 & 1.10 & 0.73 \\
Salt & 0.50 & 0.50 & 0.50 \\
Premix ${ }^{a}$ & 0.50 & 0.50 & 0.50 \\
Total & 100 & 100 & 100 \\
Nutrient composition & & & \\
DE, MJ/kg & 8.65 & 11.43 & 10.74 \\
CP \% & 11.77 & 11.76 & 11.77 \\
NDF \% & 44.81 & 26.53 & 36.26 \\
ADF \% & 24.63 & 13.45 & 22.23 \\
Ash \% & 10.26 & 8.13 & 8.52 \\
\hline
\end{tabular}

The premix consisted of the following ingredients per $\mathrm{kg}$ of diet: $6.60 \times 104 \mathrm{IU}$ of vitamin A, $8.00 \times 105 \mathrm{IU}$ of vitamin D3, $1.49 \times 103$ of vitamin $\mathrm{E}, 35.2 \mathrm{mg}$ of $\mathrm{Cu}, 120 \mathrm{mg}$ of Fe, $115 \mathrm{mg}$ of $\mathrm{Zn}, 80 \mathrm{mg}$ of $\mathrm{Mn}, 0.35 \mathrm{mg}$ of $\mathrm{Co}$, and $19.5 \mathrm{mg}$ of $\mathrm{Se}$

and C06PJB purchased from the Beijing North Institute of Biological Technology with a detection limit of $0.1-$ $8.1 \mathrm{ng} / \mathrm{mL}, 50-4000 \mathrm{pg} / \mathrm{mL}$ and $9-590 \mathrm{fmol} / \mathrm{mL}$.

\section{Histological analysis}

Fixed tissues were embedded in paraffin after immersing in a $4 \%$ paraformaldehyde solution for $72 \mathrm{~h}$ and dehydrating by ethanol. Five micrometer sections were cut form the paraffin on a microtome, mounted on slides, and stained with haematoxylin and eosin. The images were recorded by light microscope and high-resolution digital camera. Histological damage was assessed with a scoring epithelial injury criteria (graded 0 to 3 ) which has been described previously [45].

\section{Quantitative real-time PCR}

$100 \mathrm{mg}$ colonic tissue samples were selected for RNA extraction using RNAiso Plus (TaKaRa, Otsu, Japan). The A260/A230 and A260/A280 ratio of RNA samples were measured by spectrophotometer (Thermo Fisher Scientific Inc., Waltham, MA, United States). Then, RNA was reverse transcribed to the first-strand cDNA by PrimeScript RT kit (Cat. RR036A; TaKaRa). Primers were designed and synthesized in Shanghai Sangon Biotech Co., Ltd. and are listed in Table 3. Quantitative real-time PCR was performed using a SYBR Premix EX Taq Kit (Cat. DRR420A; TaKaRa) via an ABI 7300 system (Applied Biosystems, Foster City, CA, USA) according to the manufacturer's protocol. Glyceraldehyde-3-phosphate dehydrogenase (GAPDH) was used as the internal reference and the data was analyzed by $2^{-\Delta \Delta C t}$ method.

\section{Western blot analysis}

Approximately $100 \mathrm{mg}$ of frozen grated colonic tissue was homogenized in $1 \mathrm{~mL}$ ice-cold RIPA protein isolation buffer (Cat. No. SN338; Sunshine Biotechnology Co., Nanjing, China) for the total protein extraction. The protein concentration was measured via the BCA Protein Assay kit (No. 23225, Thermo Fisher, USA). $50 \mu \mathrm{g}$ of total protein was loaded onto $12 \%$ sodium dodecyl sulfate-polyacrylamide gel electrophoresis (SDS-PAGE) and transferred to a nitrocellulose membrane (Bio Trace; Pall Co., Port Washington, NY). The membranes were incubated in the appropriate primary antibodies: Jun N-terminal kinase (JNK) (No. 9252S; Cell Signaling Technology, Danvers, MA), p-JNK (No. 9255S; Cell Signaling Technology), p38 (No. 8690S; Cell Signaling Technology), p-p38 (No. 4511S; Cell Signaling Technology), Erk1/2 (No. 4695S; Cell Signaling Technology), p-Erk1/2 (No. 4370S; Cell Signaling Technology), PKC-

Table 3 The primer sequences of target and internal reference genes used in qRT-PCR

\begin{tabular}{llll}
\hline Gene & Forward primer & Reverse primer & PCR products (bp) \\
\hline Erk1 & CTCAGCTTACGACCATGTGC & TCAGGTCCTGCACGATGTAG & 203 \\
Erk2 & CTCAGCAACGACCACATCTG & CCAGGCCAAAGTCACAGATC & 151 \\
p38 & ACAACATCGTCAAGTGCCAG & CACGTAGCCAGTCATCTCCT & 209 \\
JNK & ACAudin-1 & ACTTATGCCTGCTCTGCTCA & 229 \\
Claudin-4 & AGCCAATGAAGAGAGCCTGA & 216 \\
Occludin & CACCCTTGGCATGAAGTGTA & GACGTTGTTAGCCGTCCAG & 238 \\
ZO-1 & AAGGTGTACGACTCGCTGCT & CAGCTCCCATTAAGGTCCA & 200 \\
GAPDH & GTCGACCAATGCTCTCTCAG & AATCACCCACATCGGATTCT & 163 \\
\hline
\end{tabular}


(No. 2056S; Cell Signaling Technology), occludin (No. ab167161; Abcam, Cambridge, United Kingdom), claudin-1 (No. ab15098; Abcam), and ZO-1 (No. ab214228; Abcam), then washed and incubated in corresponding horseradish peroxidase (HRP)-conjugated secondary antibodies. Finally, the membranes were washed and visualized using an enhanced chemiluminescence (ECL) Kit (Pierce, Rockford, IL). The signals were recorded using an Bio-Rad imaging system (Bio-Rad, Hercules, CA), and the results were analyzed using Quantity One software (Bio-Rad).

\section{Statistical analysis}

The results are expressed as the mean \pm standard error of the mean (SEM). All data were evaluated with an unpaired Student's t-test or one-way ANOVA with the SPSS 21.0 statistical software package. A $P$ value $<0.05$ was considered to indicate a significant difference.

\section{Abbreviations}

ERK: Extracellular regulated protein kinases; HC: High-concentrate diet; JNK: CJun N-terminal kinase; LC: Low-concentrate diet; LPS: Lipopolysaccharide; MAPK: Mitogen-activated protein kinase; SARA: Subacute ruminal acidosis; SH: Soybean hulls; TJ: Tight junction; TNF-a: Tumour necrosis factor a

\section{Acknowledgements}

The authors would like to thank Qian Song and Jian Liu for animal feeding.

\section{Author contributions}

YFB and KZ conceived and designed the experiments. LPG, MJM, and YLT assisted in feeding animals and sampling. KZ and MJM conducted the research and analysed the data. KZ prepared the manuscript. YFB finalized the manuscript. All authors read and approved the final manuscript.

\section{Funding}

This study was supported by the Project of Jiang Su Independent Innovation (CX(15)1003) and Postdoctoral Foundation of Jiangsu Province (Grant number 1701031A). The funders had no role in the design of the study and collection, analysis, and interpretation of data and in writing the manuscript.

\section{Availability of data and materials}

All data presented in this article are available upon request.

\section{Ethics approval and consent to participate}

The protocols for the care and use of animals in this study were approved by the guidelines of Jiangsu Province Animal Regulations (Government Decree No. 45) and the Committee on the Ethics of Animal Experiments of Jiangsu Academy of Agricultural Sciences.All the experimental protocols were performed in accordance with the approved guidelines and regulations.

\section{Consent for publication}

Not applicable.

\section{Competing interests}

The authors declare that they have no competing interests.

\section{Publisher's Note}

Springer Nature remains neutral with regard to jurisdictional claims in published maps and institutional affiliations.
Received: 20 February 2018 Accepted: 21 November 2018

Published online: 03 December 2018

\section{References}

1. Li S, Khafipour E, Krause D, Kroeker A, Rodriguez-Lecompte J, Gozho G, et al. Effects of subacute ruminal acidosis challenges on fermentation and endotoxins in the rumen and hindgut of dairy cows. J Dairy Sci. 2012;95(1): 294-303.

2. Steele MA, Croom J, Kahler M, AlZahal O, Hook SE, Plaizier K, et al. Bovine rumen epithelium undergoes rapid structural adaptations during graininduced subacute ruminal acidosis. Am J Physiol Regul Integr Comp Physiol. 2011;300(6):R1515-23.

3. Zhou J, Dong G, Ao C, Zhang S, Oiu M, Wang X, et al. Feeding a highconcentrate corn straw diet increased the release of endotoxin in the rumen and pro-inflammatory cytokines in the mammary gland of dairy cows. BMC Vet Res. 2014;10(1):172.

4. Gott P, Hogan JS, Weiss WP. Effects of various starch feeding regimens on responses of dairy cows to intramammary lipopolysaccharide infusion. J Dairy Sci. 2015;98(3):1786-96.

5. Khafipour E, Krause DO, Plaizier JC. Alfalfa pellet-induced subacute rumina acidosis in dairy cows increases bacterial endotoxin in the rumen without causing inflammation. J Dairy Sci. 2009:92:1712-24.

6. Plaizier J, Khafipour E, Li S, Gozho G, Krause D. Subacute ruminal acidosis (SARA), endotoxins and health consequences. Anim Feed Sci Tech. 2012; 172:9-21.

7. Nagaraja TG, Titgemeyer EC. Ruminal acidosis in beef cattle: The current microbiological and nutritional outlook1,2. J Dairy Sci. 2007;90:E17-38.

8. Gozho GN, Krause DO, Plaizier JC. Ruminal lipopolysaccharide concentration and inflammatory response during grain-induced subacute ruminal acidosis in dairy cows. J Dairy Sci. 2007:90:856-66.

9. Gareau MG, Silva MA, Perdue MH. Pathophysiological mechanisms of stressinduced intestinal damage. Curr Mol Med. 2008:8:274-81.

10. Mao S, Zhang R, Wang D, Zhu W. The diversity of the fecal bacterial community and its relationship with the concentration of volatile fatty acids in the feces during subacute rumen acidosis in dairy cows. BMC Vet Res. 2012;8(237):1746-6148

11. Liu JH, Xu TT, Liu YJ, Zhu WY, Mao SY. A high-grain diet causes massive disruption of ruminal epithelial tight junctions in goats. Am J Physiol Regul Integr Comp Physiol. 2013;305:R232-41.

12. Gassler N, Rohr C, Schneider A, Kartenbeck J, Bach A, Overmuller N, et al. Inflammatory bowel disease is associated with changes of enterocytic junctions. Am J Physiol Gastrointest Liver Physiol. 2001;281:G216-28.

13. Heller F, Florian P, Bojarski C, Richter J, Christ M, Hillenbrand B, et al. Interleukin-13 is the key effector Th2 cytokine in ulcerative colitis that affects epithelial tight junctions, apoptosis, and cell restitution. Gastroenterology. 2005:129:550-64.

14. Poritz LS, Harris LR 3rd, Kelly AA, Koltun WA. Increase in the tight junction protein claudin-1 in intestinal inflammation. Dig Dis Sci. 2011:56:2802-9.

15. John LJ, Fromm M, Schulzke JD. Epithelial barriers in intestinal inflammation. Antioxid Redox Signal. 2011;15(5):1255-70.

16. Matter K, Balda MS. Occludin and the functions of tight junctions. Int Rev Cytol. 1999;186:117-46

17. Feldman GJ, Mullin JM, Ryan MP. Occludin: structure, function and regulation. Adv Drug Deliv Rev. 2005:57:883-917

18. McCarthy KM, Skare IB, Stankewich MC, Furuse M, Tsukita S, Rogers RA, et al. Occludin is a functional component of the tight junction. J Cell Sci. 1996; 109:2287-98.

19. Balda MS, Matter K. Tight junctions and the regulation of gene expression Biochim Biophys Acta. 2009:1788:761-7.

20. Vietor I, Bader T, Paiha K, Huber LA. Perturbation of the tight junction permeability barrier by occludin loop peptides activates beta-catenin/TCF/ LEF-mediated transcription. EMBO Rep. 2001;2:306-12.

21. Saitou M, Furuse M, Sasaki H, Schulzke JD, Fromm M, Takano H, et al. Complex phenotype of mice lacking occludin, acomponent of tight junction strands. Mol Biol Cell. 2000;11:4131-42.

22. Yu AL, McCarthy KM, Francis SA, McCormack JM, Lai J, Rogers RA, et al. Knock down of occludin expression leads to diverse phenotypic alterations in epithelial cells. Am J Physiol Cell Physiol. 2005;288:C1231-41.

23. Furuse M, Fujita K, Hiiragi T, Fujimoto K, Tsukita S. Claudin-1 and -2:novel integral membrane proteins localizing at tight junctions with no sequence similarity to occludin. J Cell Biol. 1998a;141:1539-50. 
24. Muto S, Furuse M, Kusano E. Claudins and renal salt transport. Clin Exp Nephrol. 2012;16(1):61-7.

25. Furuse M, Furuse K, Sasaki H, Tsukita S. Conversion of zonulae occludentes from tight to leaky strand type by introducing claudin-2 into Madin-Darby canine kidney I cells. J Cell Biol. 2001;153:263-72.

26. Tsukita S, Furuse M, Itoh M. Multifunctional strands in tight junctions. Nat Rev Mol Cell Biol. 2001;2:286-93.

27. Bazzoni G, Martinez-Estrada OM, Orsenigo F, Cordenonsi M, Citi S, Dejana E. Interaction of junctional adhesion molecule with the tight junction components ZO-1, cingulin, and occludin. J Biol Chem. 2000;275:20520-6.

28. Umeda K, Ikenouchi J, Katahira-Tayama S, Furuse K, Sasaki H, Nakayama M, et al. ZO-1 and ZO-2 independently determine where claudins are polymerized in tight junction strand formation. Cell. 2006;126:741-54.

29. Naydenov NG, Hopkins AM, Ivanov Al. C-Jun N-terminal kinase mediates disassembly of apical junctions in model intestinal epithelia. Cell Cycle. 2009:8:2110-21.

30. Lee MH, Koria P, Qu J, Andreadis ST. JNK phosphorylates beta-catenin and regulates adherens junctions. FASEB J. 2009;23:3874-83.

31. Ranathunga SD, Kalscheur KF, Hippen AR, Schingoethe DJ. Replacement of starch from corn with nonforage fiber from distillers grains and soyhulls in diets of lactating dairy cows. J Dairy Sci. 2010;93:1086-97.

32. Emmanuel DG, Dunn SM, Ametaj BN. Feeding high proportions of barley grain stimulates an inflammatory response in dairy cows. J Dairy Sci. 2008; 91:606-14.

33. Castrillo C, Mota M, Van LH, Martín-Tereso J, Gimeno A, Fondevila M, et al. Effect of compound feed pelleting and die diameter on rumen fermentation in beef cattle fed high concentrate diets. Anim Feed Sci Technol. 2013;180:34-43.

34. Penner GB, Steele MA, Aschenbach JR, McBride BW. Ruminant nutrition symposium: molecular adaptation of ruminal epithelia to highly fermentable diets. J Anim Sci. 2011;89:1108-19.

35. Klevenhusen F, Hollmann M, Podstatzky-Lichtenstein L, Krametter-Frotscher $\mathrm{R}$, Aschenbach JR, Zebeli Q. Feeding barley grain-rich diets altered electrophysiological properties and permeability of the ruminal wall in a goat model. J Dairy Sci. 2013;96:2293-302.

36. Kenichi T, Takashi K, Norimasa S, Tetsuo H. Role of tight junctions in signal transduction: an update. EXCLI J. 2014:13:1145-62.

37. Carrozzino F, Pugnale P, Féraille E, Montesano R. Inhibition of basal p38 or JNK activity enhances epithelial barrier function through differential modulation of claudin expression. Am J Physiol Cell Physiol. 2009;297:C77587.

38. Kojima T, Fuchimoto J, Yamaguchi H, Ito T, Takasawa A, Ninomiya T, et al. CJun $\mathrm{N}$-terminal kinase is largely involved in the regulation of tricellular tight junctions via tricellulin in human pancreatic duct epithelial cells. J Cell Physiol. 2010;225:720-33

39. Guo J, Chang G, Zhang K, Xu L, Jin D, Bilal MS, et al. Rumen-derived lipopolysaccharide provoked inflammatory injury in the liver of dairy cows fed a high-concentrate diet. Oncotarget. 2017. https://doi.org/10.18632/ oncotarget.

40. Li D, Mrsny RJ. Oncogenic Raf-1 disrupts epithelial tight junctions via downregulation of occludin. J Cell Biol. 2000;148:791-800.

41. Kojima T, Yamamoto T, Murata M, Chiba H, Kokai Y, Sawada N. Regulation of the blood-biliary barrier:interaction between gap and tight junctions in hepatocytes. Med Electron Microsc. 2003;36:157-64.

42. Yamamoto T, Kojima T, Murata M, Takano K, Go M, Hatakeyama N, et al. p38 MAP-kinase regulates function of gap and tight junctions during regeneration of rat hepatocytes. J Hepatol. 2005:42:707-18.

43. Saadat I, Higashi H, Obuse C, Umeda M, Murata-Kamiya N, Saito Y, et al. Helicobacter pylori CagA targets PAR1/MARK kinase to disrupt epithelial cell polarity. Nature. 2007:447:330-3.

44. Stumpff F, Georgi MI, Mundhenk L, Rabbani I, Fromm M, Martens H, et al. Sheep rumen and omasum primary cultures and source epithelia: barrier function aligns with expression of tight junction proteins. J Exp Biol. 2011; 214:2871-82.

45. Wu X, Vallance BA, Boyer L, Bergstrom KS, Walker J, Madsen K, et al. Saccharomyces boulardii ameliorates Citrobacter rodentium-induced colitis through actions on bacterial virulence factors. Am J Physiol Gastrointest Liver Physiol. 2008:294:G295-306.

Ready to submit your research? Choose BMC and benefit from:

- fast, convenient online submission

- thorough peer review by experienced researchers in your field

- rapid publication on acceptance

- support for research data, including large and complex data types

- gold Open Access which fosters wider collaboration and increased citations

- maximum visibility for your research: over $100 \mathrm{M}$ website views per year

At BMC, research is always in progress.

Learn more biomedcentral.com/submissions 